\title{
Scales to assess impulsive and compulsive behaviors in Parkinson's disease: critique and recommendations
}

Andrew H Evans, FRACP, MD, ${ }^{1}$ David Okai, MRCPsych, MB.BS, ${ }^{2}$ Daniel Weintraub, MD, Shen-Yang Lim, FRACP, MD, ${ }^{3}$ Sean O'Sullivan, FRCP, PhD, ${ }^{4}{ }^{5}$ Valerie Voon, MD, PhD, ${ }^{6}$ Paul Krack, MD, PhD, ${ }^{7}$ Cristina Sampaio, MD, ${ }^{8}$ Bart Post ${ }^{9}$, Albert Leentjens, $\mathrm{PhD}^{10}$ Pablo Martinez-Martin, MD, PhD ${ }^{10}$ Glenn T. Stebbins, PhD, ${ }^{12}$ Christopher G. Goetz, MD, ${ }^{12}$ Anette Schrag, MD, PhD ${ }^{13}$ and the Members of the IPMDS Rating Scales Review Committee

${ }^{1}$ Department of Neurology, the Royal Melbourne Hospital, Parkville, Australia

${ }^{2}$ Kings College London, Institute of Psychiatry, Section of Cognitive Neuropsychiatry, UK ${ }^{3}$ Department of Psychiatry, University of Pennsylvania, Philadelphia, Pennsylvania and Parkinson's Disease and Mental Illness Research, Education and Clinical Centers (PADRECC and MIRECC), Philadelphia Veterans Affairs Medical Center, USA ${ }^{4}$ Faculty of Medicine, University of Malaya, Kuala Lumpur, Malaysia

${ }^{5}$ Department of Neurology, Cork University Hospital, Ireland

${ }^{6}$ Dept of Psychiatry, Univ. of Cambridge, Cambridge, UK

${ }^{7}$ Grenoble Institute of Neuroscience, Inserm U836, Univ. Grenoble Alpes, and Movement Disorder Unit, CHU de Grenoble, F-38000 Grenoble, France

${ }^{8} \mathrm{CHDI}$ Management/CHDI Foundation, Princeton, New Jersey, USA

${ }^{9}$ Department of Neurology, Radboud University Nijmegen Medical Center, Nijmegen, The Netherlands

${ }^{10}$ Department of Psychiatry, Maastricht University Hospital, Maastricht, the Netherlands

This is the author manuscript accepted for publication and has undergone full peer review but has not been through the copyediting, typesetting, pagination and proofreading process, which may lead to differences between this version and the Version of Record. Please cite this article as doi: $10.1002 /$ mds.27689

This article is protected by copyright. All rights reserved. 
${ }^{11}$ National Center of Epidemiology and CIBERNED, Carlos III Institute of Health, Madrid, Spain

${ }^{12}$ Department of Neurological Sciences, Rush University Medical Center, Chicago, Illinois, USA

${ }^{13}$ Department of Clinical Neurosciences, Institute of Neurology, University College London, London, UK

Key Words: impulse control disorders; Parkinson's disease; clinimetrics; rating scales;

validity; reliability

Running title: Scales to assess impulsive and compulsive behaviors in Parkinson's disease

\section{Correspondence:}

Andrew H Evans, FRACP, MD

Department of Neurology,

The Royal Melbourne Hospital

Grattan St Parkville VIC Australia 3050

Phone + 61393428448

Fax +61393428427

Email: Andrew.Evans@mh.org.au

This article is protected by copyright. All rights reserved. 


\section{Financial disclosure related to research covered in this article}

Andrew $\mathrm{H}$. Evans, has received reimbursement of travel expenses to scientific meetings or honoraria for lecturing or consultation from UCB, Teva, Abbott, AbbVie, Stada, Allergan. Dr Evans holds shares in CSL and Global Kinetics Corporation.

David Okai: None

Sean O'Sullivan: Honoraria from UCB Pharma, Orion Pharma, Teva, Britannia, and consultancy fees from Britannia pharmaceuticals

Daniel Weintraub: Research funding or support from Michael J. Fox Foundation for

Parkinson's Research, National Institutes of Health (NINDS), Novartis Pharmaceuticals,

Department of Veterans Affairs, Avid Radiopharmaceuticals, Alzheimer's Disease

Cooperative Study, and the International Parkinson and Movement Disorder Society;

honoraria from AbbVie, Acadia, Biogen, Biotie, Clintrex LLC, Janssen, Merck, Novartis,

Pfizer, Teva Pharmaceuticals, UCB, and the CHDI Foundation; license fee payments from

the University of Pennsylvania for the QUIP and QUIP-RS; royalties from Wolters Kluweland;

and fees for legal consultation for lawsuit related to antipsychotic prescribing in a patient with

Parkinson's disease.

Cristina Sampaio: None

Olivier Rascol: None

Martinez-Martin P: Funding from UCB for the validation study of the Scale for Evaluation of Neuropsychiatric Disorders in Parkinson's disease (SEND-PD), and from the International

Parkinson and Movement Disorder Society for the Pilot Study of the MDS-Non-Motor

Symptoms Scale.

Glenn T. Stebbins: Funding from the International Parkinson and Movement Disorder

Society for examination of missing values and differential item function analyses of the MDSUPDRS

Christopher G. Goetz: Funding from the International Parkinson and Movement Disorder

Society for examination of missing values and differential item function analyses of the MDSUPDRS

Anette Schrag: Funding from the International Parkinson and Movement Disorder Society for development of the MDS-NMS

Shen-Yang Lim: Honoraria from Boehringer Ingelheim and grants from the Malaysian

Ministry of Education (HIR grant UM.0000017/HIR.C3).

Paul Krack: Funding from Medtronic, St Jude and Boston Scientific for research purposes in the field of deep brain stimulation and received research support from France Parkinson, INSERM (French National Institute of Health and Research in Medicine), Edmond J.\& Lily Safra Foundation, Grenoble University Hospital, Orkyn, Novartis, UCB, LVL, Boston Scientific. He received reimbursement of travel expenses to scientific meetings or honoraria for lecturing or consultation from Medtronic, Euthérapie Company, Novartis Pharma, UCB, St. Jude, Lundbeck, Boehringer Ingelheim, Orkyn, Abbott, Orion, TEVA and Boston Scientific.

This article is protected by copyright. All rights reserved. 


\begin{abstract}
Impulse control disorders (ICDs) and related impulsive and compulsive behaviors (together called ICBs) have been increasingly recognized in the context of Parkinson's disease (PD) and treatment. The International Parkinson's and Movement Disorder Society commissioned a task force to assess available clinical screening instruments and rating scales, including their clinimetric properties, to make recommendations regarding their utility, and to suggest future directions in scale development and validation. The literature was systematically searched for scales measuring a range of reported ICBs in PD. A scale was designated "Recommended" if the scale had been employed in PD studies, been used beyond the group that developed it, and had adequate clinimetric data published in PD. Numerous diagnostic screening tools and severity rating scales were identified for a range of ICBs, including compulsive medication use (CMU), punding/hobbyism, walkabout, pathological gambling, hypersexuality, compulsive or binge eating, compulsive buying, reckless driving, compulsive exercise, pyromania, trichotillomania, hoarding, kleptomania, intermittent explosive disorder, and internet addiction.
\end{abstract}

For screening across the range of ICBs (except CMU), the Questionnaire for ImpulsiveCompulsive Disorders in Parkinson's disease (QUIP) and QUIP-Rating Scale (QUIP-RS) are Recommended, and for severity rating across the range of ICBs the QUIP-RS and the Ardouin Scale of Behavior in Parkinson's Disease are Recommended. The Scale for Outcomes in Parkinson's Disease - Psychiatric Complications (SCOPA-PC) is Recommended for rating of hypersexuality and the compulsive behaviors gambling/shopping. Further testing of established scales against gold standard diagnostic criteria is urgently required for all other individual ICBs in PD. 


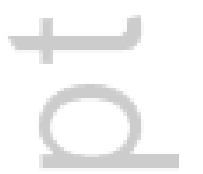

This article is protected by copyright. All rights reserved. 


\section{INTRODUCTION}

Impulsive and compulsive behaviors (ICBs) have been increasingly recognized in the context of Parkinson's disease (PD) treatment. These ICBs are linked by their repetitive, reward or incentive-based natures, and include a range of impulse control disorders (ICDs) (i.e., pathological gambling (PG), hypersexuality (HS), compulsive or binge eating (CE), compulsive buying (CB)), ${ }^{1}$ as well as related behaviors, including punding, walkabout, and compulsive medication use (CMU), the latter also known as dopamine dysregulation syndrome (DDS).

ICDs are defined by a failure to resist an impulse, drive, or temptation to perform an act that is harmful to the person or to others. The largest systematic prevalence study in North American PD outpatients estimated that at least $14 \%{ }^{2}$ have one or more current ICDs according to criteria. Cross-sectional evaluations of PD outpatient populations indicate that ICDs are more prevalent when compared with the general population or with control subjects, and are associated with the drugs used to treat the motor symptoms of PD., 3 However, prevalence estimates of ICDs in PD vary widely: from $3.5 \%{ }^{4}$ to $35 \%{ }^{5}$ reflecting variability in case ascertainment, definitions, prescribing practices and cultural factors. ${ }^{1}$ Recently, 5 year cumulative incidence of ICDs in treated Parkinson's was estimated at $46.1 \%{ }^{6}$

ICDs in PD increase caregiver burden ${ }^{7}$, and adversely affect occupational functioning, finances, and interpersonal relationships. Despite this, ICBs frequently go unrecognized and represent a major clinical challenge for routine detection ${ }^{8,9}$ - potentially prolonging the psychosocial consequences associated with them. ICBs also represent a major management challenge once identified. ${ }^{10}$

Simple, short, self-administered but sensitive screening questionnaires are therefore needed to potentially prevent or detect ICBs in clinical practice. Rating scales are required to aid categorization, measurement of the symptom severity, support entry criteria for research studies, assist in neurobiological studies, and to measure and test clinical responses to psychosocial and medication treatments as part of clinical trials. ${ }^{11}$ Uniform diagnostic criteria

This article is protected by copyright. All rights reserved. 
for ICBs in PD currently do not exist but would aid generalizability of the study of vulnerability factors and outcomes to clinical practice.

For these reasons, the International Parkinson and Movement Disorder Society (MDS) commissioned a systematic review of the clinimetric properties of the screening tools and scales used to detect, diagnose and rate ICBs in PD. MDS-sponsored reviews of scales for assessing other aspects of PD have already been published, and the methodology of this review is similar. ${ }^{12,13}$

\section{METHODS}

\section{Administrative Organization and Critique Process}

The steering committee of the MDS task force on rating scales for PD invited the chair (AHE) to form a task force to critique existing ICD rating scales. This group used the same working methods as previous task forces. ${ }^{11,12}$ The review used a proforma which includes descriptive properties, availability, content, use, acceptability, clinimetric properties and overall impression in patients with PD (see appendix).

Two task force members reviewed each scale. The completed reviews were then assessed by all other members following terminology used in the development of the Appendix of ancillary scales to complement the MDS-sponsored revision of the UPDRS.

The official definitions for critiques are: "Recommended" for diagnostic screening or severity rating of ICBs if, for this purpose, 1) it has been applied to PD populations, 2) there are data on its use in studies beyond one group, and 3 ) it has been studied clinimetrically and adequate clinimetric data are reported in PD (for this review that the instrument was found to be adequate for screening purposes, measuring severity of symptoms, or assessing responsiveness to change); "Suggested" if it has been applied to PD populations, but only one of the other criteria applies; or "Listed" if it has only been applied to PD populations. Scales classified as Suggested or Recommended and have at least some validation data in PD are listed in the tables, with only the Recommended scales included in the results. Full results of all scales, included those that are used in PD but only validated in non-PD populations, are available in the appendix. The ratings of Recommended, Suggested and

This article is protected by copyright. All rights reserved. 
Listed have been applied to two different uses: screening tools to detect the presence or absence of ICDs, and severity rating scales to detect the magnitude of ICD impact.

\section{Literature Search Strategy}

We searched for scales that were designed to screen/diagnose and measure the severity of ICBs and were either used in studies with PD patients up to February 2018. We searched Medline and PubMed databases: Search terms used included Parkinson's disease OR Parkinsonism AND impulse control disorder OR compulsive, gambling, hypersexuality, paraphilia, eating, addiction, hoarding, dopamine dysregulation syndrome, hedonistic homeostatic dysregulation, punding, hobbyism, reckless driving, buying, and shopping. Published or in press peer-reviewed papers and their references or abstracts known to the task force members were also considered in this review.

\section{Results}

Fifty scales used for whole or individual ICBs were identified. We describe here those instruments that met criteria for Recommended and give further details on all reviewed instruments in the appendix (Supplementary material), including their description, clinimetric data, and scope of use.

Table 1 lists all instruments fulfilling criteria for Recommended or Suggested scales to measure the presence or absence of ICBs.

\section{Instruments for the range of ICBs}

\section{The Questionnaire for Impulsive-Compulsive Disorders in Parkinson's disease $(\text { QUIP) })^{14}$}

The QUIP was developed as a screening instrument for ICDs and related behaviors. The authors of the QUIP reviewed existing scales for ICDs, solicited input from outside experts in the area of ICDs in PD, and structured the ICD questions to be consistent with diagnostic criteria or defining clinical characteristics as described in the Diagnostic and Statistical Manual Edition IV-Text Revised (DSM-IV-TR). ${ }^{15}$ The full version was divided into three 
sections: (1) five questions (including an introductory question describing the problem behaviors) for the four commonest ICDs reported in PD; (2) three distinct introductory questions and two additional questions for hobbyism, punding, and walkabout; and (3) five questions (including an introductory question) for CMU. A shortened version of the ICD section was constructed (QUIP-S) using two questions for each disorder (8 total questions).

Use in PD and Extent of Use

The QUIP was developed and validated in PD and has been used by the developers and many other groups. ${ }^{5,16-20}$

Clinimetric properties

The individual QUIP subscales were validated against a gold standard semi-structured interview for $\mathrm{PG},{ }^{21} \mathrm{CB},{ }^{22} \mathrm{HS},{ }^{23} \mathrm{CE},{ }^{21} \mathrm{DDS},{ }^{24}$ punding, ${ }^{24}$ hobbyism, ${ }^{25}$ and walkabout. ${ }^{24}$ The discriminant validity of the QUIP was high for each disorder or behavior (receiver operating characteristic area under the curve [ROC AUC]: gambling $=0.95$, sexual behavior $=0.97$, buying $=0.87$, eating $=0.88$, punding $=0.78$, hobbyism $=0.93$, walkabout $=0.79$ ). On post hoc analysis, the QUIP-S ICD section had similar properties (ROC AUC: gambling=0.95, sexual behavior $=0.96$, buying $=0.87$, eating $=0.88$ ). When disorders/behaviors were combined, the sensitivity of the QUIP to detect an individual with any disorder was $96 \% .{ }^{20}$ Sensitivity of the QUIP for a diagnosed ICD was $100 \%$ for both patient- and informant-completed instruments, and specificity was $75 \%$ for both raters. Agreement between patient- and informant-reporting of any ICD behaviors on the QUIP was moderate (averaged $\mathrm{k}=0.41$ ), and for individual ICDs was highest for gambling $(\mathrm{k}=0.55)$ and lowest for eating $(\mathrm{k}=0.40)$. However, approximately $40 \%$ of patients without an ICD diagnosis were found to have a positive QUIP, suggesting either over identification or that many PD patients experience subsyndromal ICD symptoms that require ongoing monitoring. ${ }^{9}$

\section{Strengths and Weaknesses}

The QUIP is currently the only validated screening instrument for the most commonly reported ICBs in PD. It is self-rated, and brief with generally good diagnostic accuracy overall for most individual ICBs. However, it does not enquire about a change in preference

This article is protected by copyright. All rights reserved. 
for sweet foods that may miss some aspects of compulsive eating behavior ${ }^{26}$ It has limited sensitivity for punding and walkabout (60-65\%) and limited validity for CMU. It is not designed to evaluate severity of ICBs. There is poor agreement between informant's and

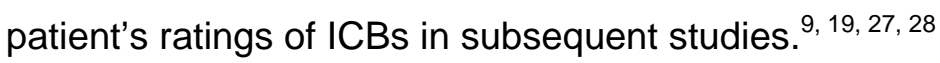

\section{Final Assessment}

The QUIP fulfills criteria for a recommended scale for screening for a range of ICBs, except punding, walkabout and $\mathrm{CMU}$, as it fulfills all three criteria, but has not been evaluated as a measure of severity (table 1 ).

\section{The Questionnaire for Impulsive-Compulsive Disorders in Parkinson's disease - Rating Scale (QUIP-RS) ${ }^{14}$}

The QUIP-RS is a brief 28-item patient-reported or clinician-rated scale that was developed in PD and derived from the QUIP for measure of severity of ICDs. Each item is rated on a 5point Likert scale assessing frequency of symptoms with a range of scores from 0 (Never) to 4 (Very Often). The questions relate to the four commonest ICDs (PG, CE, CB, and HS), hobbyism and punding (combined as a single diagnosis), and CMU over the preceding four weeks.

Use in PD and Extent of Use

At a movement disorders clinic, a convenience sample of PD patients self-completed the QUIP-RS and were administered a semi-structured diagnostic interview by a blinded trained rater to assess discriminant validity for impulse control disorders $(n=104)$ and related disorders $(n=77)$. The QUIP-RS has been used by others. ${ }^{29,} 30$

Clinimetric properties

To determine criterion validity of the self-completed QUIP-RS $(n=104)$ participants were administered a semi-structured diagnostic interview for $\mathrm{PG},{ }^{15} \mathrm{CB},{ }^{22} \mathrm{HS},{ }^{23}$ and $\mathrm{CE},{ }^{15}$ and a subset of participants was also administered a diagnostic interview for hobbyism, ${ }^{25}$ punding and DDS. ${ }^{24} \mathrm{~A}$ diagnosis of compulsive gambling included those patients with either problem

This article is protected by copyright. All rights reserved. 
or pathological gambling. ${ }^{31}$ The optimal cutoff point for individual ICDs (possible score 0-16 for each ICD) were as follows: gambling $\geq 6$ ( $L R+=33.33$, $L R-=0.00, A \cup C=0.997)$; buying $\geq 8(L R+=16.40, L R-=0.19, A \cup C=0.969) ; \operatorname{sex} \geq 8(L R+=9.09, L R-=0.00, A \cup C=0.979) ;$ and eating $\geq 7(L R+=4.35, L R-=0.16, A \cup C=0.913)$. For combined ICDs (possible score $0-64)$ the optimal cutoff point was $\geq 10$ ( $L R+=5.38$, LR- $=0.17$, AUC $=0.907)$. Hobbyismpunding (possible score 0-32) had an optimal cutoff point of $\geq 7(L R+=5.29$, LR- $=0.12$, $A \cup C=0.873) .{ }^{14}$ However, others have reported sensitivities and specificities that were not as good. ${ }^{30}$ Cut-off points for CMU screening have not been established and therefore not validated for this. The reliability between patient- and clinician-rating and test-retest reliability (intraclass correlation coefficient) were $>0.60$ for all disorders. Inter-rater reliability between different raters when clinician-rated has not been assessed. The QUIP-RS was validated against a number of other neuropsychiatric measures. ${ }^{32}$ It has been used as an outcome measure ${ }^{33,34}$ and shows sensitivity to change. Participants in an ICD treatment randomized controlled trial showed significant $(p=0.04)$ improvement on active (naltrexone) compared with placebo treatment on the QUIP-RS, with estimated changes in QUIP-RS ICD scores from baseline to week 8 of 14.9 points (naltrexone) vs. 7.5 points (placebo). ${ }^{35}$

\section{Strengths and Weaknesses}

The QUIP-RS appears to be valid and reliable for rating of severity of ICDs in PD, but not DDS. Preliminary results suggest that it can also be used to support as a screening tool for ICDs, as well as to monitor changes in symptom severity over time. The cut-off points established in the North American sample may not be generalizable. The QUIP-RS is yet to be widely used. ${ }^{30}$

\section{Final assessment}

The QUIP-RS is Recommended, as a diagnostic screening tool for ICDs, except DDS, because it has been applied to a PD population, fulfills necessary clinimetric criteria, and has been used beyond the group that developed the scale. Likewise, it is Recommended as a severity rating tool for measuring the magnitude of ICD impact (Table 1). 


\section{Ardouin Scale of Behavior in Parkinson's Disease (ASBPD) ${ }^{36}$}

A 20-item, clinician-rated scale covering CE, CB, PG, HS punding and CMU that also includes items evaluating mood, anxiety, irritability, hallucinations-delusions, activities, emotional arousal, sleep and creativity. Patients choose from 1 of 3 sentences they feel best reflect their behavior/mood. Items are in a five-point ordinal scale (0-4 from absent to severe) with scoring derived from a semi-structured interview. Open-ended questions introduce each item, allowing patients to express themselves as freely as possible. Close-ended questions permit the rating of severity and intensity of individual ICB. This instrument provides a profile of ICB and can be used by psychologists, psychiatrists or neurologists familiar with Parkinson's disease.

\section{Use in PD and Extent of Use}

Used by the authors ${ }^{36,37}$ and has been validated in PD in a multicenter, international study. ${ }^{38}$

\section{Clinimetric properties}

Designed specifically for PD, 260 patients were assessed with the tool for ICDs. For testretest reliability the weighted kappa coefficient for items was higher than 0.40 except for risktaking behavior and dopaminergic addiction. The inter-rater reliability showed kappa values higher than 0.50 for most of the items except for nocturnal hyperactivity, risk-taking behavior, and dopaminergic addiction. Cronbach's alpha coefficient for domains ranged from 0.69 to 0.78 . Correlations with corresponding rating scales for depression, anxiety, and apathy were appropriate for all domains (rho=0.56-0.82).

\section{Strengths and weaknesses}

Brief but comprehensive standardized tool with acceptable internal consistency, convergent validity, and test-retest and inter-rater reliability for its individual components for most subscores except risk-taking behavior, dopaminergic addiction and nocturnal hyperactivity.

This article is protected by copyright. All rights reserved. 
Designed for use in PD. Use outside of the developers of the instrument somewhat limited, and criterion validity not reported.

Final assessment

The scale for dopamine dependent behaviors was utilized as a rating tool prior to validation studies. However, this scale fulfills criteria for Recommended as a severity scale on the basis that it has been studied for this purpose in PD studies and has adequate clinimetric properties.

\section{The Scale for Outcomes in Parkinson's Disease - Psychiatric Complications (SCOPA- $\mathrm{PC})^{39}$}

The SCOPA-PC is screening and severity scale that consists of a 7-item clinician-rated, semi-structured questionnaire administered to the patient and caregiver for the preceding month. It assesses a broad range of psychiatric symptoms including two items that relate to compulsive behaviors (one item for hypersexuality, and one combined item for compulsive shopping and pathological gambling). Scores range from 0 (no symptoms) to 3 (severe symptoms).

Use in PD and Extent of Use

Used by the authors ${ }^{39,40}$ and other groups..$^{41-43}$

Clinimetric properties

The SCOPA-PC was designed specifically for PD and evaluated in 106 PD patients for validation. Inter-rater and test-retest reliability indexes (weighted kappa) of the sexual preoccupation ( 0.87 and 0.88 respectively) and compulsive behavior ( 0.96 and 0.73 respectively) items were high. Among 106 patients, 15\% had sexual preoccupation item $>0$ and $10 \%$ had compulsive behavior item $>0$. The compulsive behavior had good correlation with the ICD item of the Scale for Evaluation of Neuropsychiatric Disorders in Parkinson's disease (SEND-PD) $(r s=0.52){ }^{41}$

This article is protected by copyright. All rights reserved. 
Brief and standardized tool with adequate reliability and validity demonstrated for the two items. Designed for use in PD.

The SCOPA-PC has been evaluated for ICB severity only, not as a screening tool. It covers only hypersexuality and compulsive behavior, combining gambling and shopping which does not allow distinction between the two. No studies have examined change with treatment. In application of the scale, it is recommended by the authors that information is used from both patient and caregiver, but no data are provided about the level of agreement between patient and caregiver questions.

Final assessment

The SCOPA-PC has not been utilized as a Diagnostic Screening tool. However, this scale fulfills criteria for recommended as a severity scale for hypersexuality, and the compulsive behaviors of gambling/shopping, on the basis that it has been validated for this purpose in PD studies, used by more than one research group, and has adequate clinimetric properties.

\section{DISCUSSION}

The systematic review of the available literature yielded a large number of studies and instruments that have attempted to ascertain the prevalence and severity of ICBs in various PD cohorts.

PD itself may not confer an increased risk for development of impulse control or related behavior symptoms. Given that approximately $20 \%$ of newly diagnosed PD patients report some symptoms, long-term follow-up is needed to determine if such patients are at increased risk for ICD development. ${ }^{44,45}$ Categorical rating tools that are quick and easy to administer can help clinicians screen for ICBs, identify ICBs early in their course, aid decisions regarding treatment that may include prevention and monitor pharmacological and nonpharmacological management. Moreover, it is desirable to screen

This article is protected by copyright. All rights reserved. 
for multiple ICBs in patients displaying one abnormal behavior, as presence of multiple ICBs in a given individual are associated with more severe depression, poorer quality of life $e^{5,46}$ and treatment resistance. ${ }^{47}$ Adequate validation of a scale to screen for multiple ICBs in a PD population has been demonstrated for the QUIP and the QUIP-RS. The QUIP is a categorical assessment tool that screens for a range of ICBS, but while it is sensitive to patients with an ICD it has some limitations. For instance, nearly $40 \%$ of patients without an ICD diagnosis screen positive for the QUIP - the authors suggested that this is because many PD patients experience subsyndromal ICD symptoms. However, a critical point is the current definition of an ICD is the "failure to resist an impulse, drive, or temptation to perform an act that is harmful to the person or to others". The QUIP and QUIP-RS include questions specific to the urge of performing a particular behavior. This does not necessarily involve the execution of that behavior (i.e. with increased involvement of dorsal striatal systems ${ }^{48}$ ) and may also account for the high percentage of positive at QUIP not confirmed by semistructured interview. This contrasts to the definition of CMU in the QUIP where the act of medication taking leading to harmful effects is central to the diagnosis.

Conversely, dimensional rating tools can assist clinical research to help practitioners understand the etiology and course of ICBs, and to identify the effects of treatments to improve clinical outcomes and potentially monitor patients in remission. The QUIP-RS currently has the best validity for rating a range of ICBs in PD, and cutoffs were established for individual ICBS - however, the generalizability of cutoff points to non-North American samples is lacking. Furthermore, the Ardouin short screen has also been demonstrated adequate clinimetrics for rating severity of a range of ICBS. The SCOPA-PC was designed, and is Recommended, to provide a dimensional assessment of hypersexuality and the compulsive behaviors gambling/shopping, but cannot be used as a diagnostic tool.

This work identified the need for the validity of rating scales developed in non-PD to be demonstrated for the commonest behaviors in PD, particularly PG, CE and CB, before deciding to develop new scales specific to PD. Moreover, rarely have such scales been compared directly to non-PD populations, ${ }^{44,45,49,50}$ or been applied to non-Caucasian populations where dopamine agonists, for instance, are less commonly prescribed. ${ }^{19,51} \mathrm{An}$ ongoing issue is that the agreement between patient and informant reporting of symptoms is not high, ${ }^{25}$ with no clear direction for the mismatches in reporting. ${ }^{52}$ Patient under- 
reporting of ICBs is likely more common, ${ }^{53}$ indicating a likely complex relationship between insight and addiction.

Despite the urgent need to understand ICBs further, not all scales developed for non-PD populations will be suitable for adaptation to PD and it may not be possible to transfer the results from other studies. There are important overlaps in the risk factors for ICBs in $\mathrm{PD}^{52,53}$ and non-PD populations, but there are also important differences. These differences may impact on the application of scales developed in non-PD populations to PD patients with regards to interpretation of the results and drawing conclusions about ICB in PD. For instance, the phenomenology of CE in PD is likely to be distinct from eating disorders affecting adolescents. Moreover, a scale developed to detect sexually risky behavior in HIVpositive individuals (i.e. the Sexual Compulsivity Scale ${ }^{54}$ ) may not be useful in PD patients, in whom hypersexual behavior is more likely to impair longstanding personal and social relationships, add financial burden, and rarely leads to forensic issues. Finally, relatively little focus has been given in existing scales to the social and occupational impact of ICBs, with preference for the proxy measure of frequency/intensity and focus on caregiver or social burden.

A further difficulty that this review encountered was that most ICD scales validations have been performed against the DSM-IV-TR, but this is not an uncontroversial 'gold standard' for ICDs and compulsive medication use. PG, binge-eating disorder, and hoarding are included in DSM-5, but there are no formal DSM-5 criteria for compulsive buying, hypersexual disorder and punding. Furthermore, there are many more behaviors described than can be routinely assessed in an assessment tool. In this regard, clinical interview is still likely to be the best mechanism to identify harmful behaviors.

These issues are further complicated by the uncertainty in the psychiatric literature about the classification of ICDs as to whether ICDs represent "behavioral addictions", ${ }^{55}$ and therefore share the neurobiological underpinnings of substance dependence disorders, or should be classified as an obsessive-compulsive spectrum disorder. ${ }^{56}$

In conclusion, this review has highlighted the need for further research on screening and rating scales for ICBs in PD. While validity testing for screening/diagnostic purposes has 
been done for most ICB scales, validity testing of severity scales (e.g. correlation with scales assessing similar construct) has been done very rarely. At the present time, we do not recommend the development of a new scale until the available scales are more fully assessed.

Members of the MDS Rating Scales Review Committee: Roongroj Bhidayasiri, MD, FRCP, FRCPI; Richard G. Brown, PhD; Johan Marinus, PhD; Tiago A. Mestre, MD, MSc; Mayela Rodriguez Violante, MD, MSc., Matej Skorvanek, MD, PhD

Attribution of authorship was based upon substantial intellectual contributions to the research output in a combination of:

a) Conception and design of the research described in the research output;

b) Acquisition of research data where the acquisition has required significant intellectual judgement or input;

c) Analysis and interpretation of research data where the analysis and interpretation has required significant intellectual judgement or input;

d) Drafting significant parts of the work or critically revising it so as to contribute to the interpretation presented in the research output.

Principal Author: Andrew Evans

Research Output Type: journal article

Research Output Title: Scales to assess impulsive and compulsive behaviors in Parkinson's disease: critique and recommendations

Name of intended journal/ conference/ proceedings: Movement Disorders

\section{e) Authorship Summary}

\begin{tabular}{|l|l|l|}
\hline Name & Organisation & $\begin{array}{l}\text { Contribution } \\
\mathbf{( a , b , c , ~ o r ~ d ) ~} \\
\text { See above for definitions. }\end{array}$ \\
\hline Andrew Evans & $\begin{array}{l}\text { The Royal Melbourne } \\
\text { Hospital, Victoria, } \\
\text { Australia }\end{array}$ & $a, b, c, d$ \\
\hline David Okai & $\begin{array}{l}\text { Kings College London, } \\
\text { Institute of Psychiatry, } \\
\text { Section of Cognitive } \\
\text { Neuropsychiatry, UK }\end{array}$ & $a, b, c, d$ \\
\hline Daniel Weintraub & Department of & $a, b, c, d$ \\
\hline
\end{tabular}

This article is protected by copyright. All rights reserved. 


\begin{tabular}{|c|c|c|}
\hline Name & Organisation & \begin{tabular}{|l|} 
Contribution \\
$(\mathbf{a}, \mathbf{b}, \mathbf{c}$, or $\mathbf{d})$ \\
See above for definitions.
\end{tabular} \\
\hline & $\begin{array}{l}\text { Psychiatry, University of } \\
\text { Pennsylvania, } \\
\text { Philadelphia, } \\
\text { Pennsylvania and } \\
\text { Parkinson's Disease and } \\
\text { Mental Illness Research, } \\
\text { Education and Clinical } \\
\text { Centers (PADRECC and } \\
\text { MIRECC), Philadelphia } \\
\text { Veterans Affairs Medical } \\
\text { Center, USA }\end{array}$ & \\
\hline Shen-Yang Lim & $\begin{array}{l}\text { Faculty of Medicine, } \\
\text { University of Malaya, } \\
\text { Kuala Lumpur, Malaysia }\end{array}$ & $a, b, c$ \\
\hline Sean O’Sullivan & $\begin{array}{l}\text { Department of } \\
\text { Neurology, Cork } \\
\text { University Hospital, } \\
\text { Ireland }\end{array}$ & $a, b, c$ \\
\hline Valerie Voon & $\begin{array}{l}\text { Dept of Psychiatry, Univ. } \\
\text { of Cambridge, } \\
\text { Cambridge, UK }\end{array}$ & $a, b$ \\
\hline \begin{tabular}{|l} 
Paul Krack \\
\end{tabular} & $\begin{array}{l}\text { Grenoble Institute of } \\
\text { Neuroscience, } \\
\text { Inserm U836, Univ. } \\
\text { Grenoble Alpes, and } \\
\text { Movement Disorder } \\
\text { Unit, CHU de } \\
\text { Grenoble, F-38000 } \\
\text { Grenoble, France }\end{array}$ & $a, b, c$ \\
\hline \begin{tabular}{|l} 
Cristina Sampaio \\
\end{tabular} & $\begin{array}{l}\text { CHDI } \\
\text { Management/CHDI } \\
\text { Foundation, Princeton, } \\
\text { New Jersey, USA }\end{array}$ & $a, b, c$ \\
\hline Bart Post & $\begin{array}{l}\text { Department of } \\
\text { Neurology, Radboud } \\
\text { University Nijmegen } \\
\text { Medical Center, } \\
\text { Nijmegen, The } \\
\text { Netherlands }\end{array}$ & c \\
\hline \begin{tabular}{|l|} 
Albert Leentjens \\
\end{tabular} & $\begin{array}{l}\text { Department of } \\
\text { Psychiatry, Maastricht }\end{array}$ & c \\
\hline
\end{tabular}

This article is protected by copyright. All rights reserved. 


\begin{tabular}{|c|c|c|}
\hline Name & Organisation & $\begin{array}{l}\text { Contribution } \\
\text { (a, b, c, or d) } \\
\text { See above for definitions. }\end{array}$ \\
\hline & $\begin{array}{l}\text { University Hospital, } \\
\text { Maastricht, the } \\
\text { Netherlands }\end{array}$ & \\
\hline $\begin{array}{l}\text { Pablo Martinez- } \\
\text { Martin }\end{array}$ & $\begin{array}{l}\text { National Center of } \\
\text { Epidemiology and } \\
\text { CIBERNED, Carlos III } \\
\text { Institute of Health, } \\
\text { Madrid, Spain } \\
\end{array}$ & $a, c, d$ \\
\hline Glenn Stebbins & $\begin{array}{l}\text { Department of } \\
\text { Neurological Sciences, } \\
\text { Rush University Medical } \\
\text { Center, Chicago, Illinois, } \\
\text { USA }\end{array}$ & $a, c$ \\
\hline Christopher Goetz & $\begin{array}{l}\text { Department of } \\
\text { Neurological Sciences, } \\
\text { Rush University Medical } \\
\text { Center, Chicago, Illinois, } \\
\text { USA }\end{array}$ & $a, c$ \\
\hline Annette Schrag & $\begin{array}{l}\text { Department of Clinical } \\
\text { Neurosciences, Institute } \\
\text { of Neurology, University } \\
\text { College London, } \\
\text { London, UK }\end{array}$ & $a, b, c, c$ \\
\hline $\begin{array}{l}\text { The Members of the } \\
\text { IPMDS Rating } \\
\text { Scales Review } \\
\text { Committee }\end{array}$ & Various & $a, d$ \\
\hline
\end{tabular}

This article is protected by copyright. All rights reserved. 
1. Evans AH, Strafella AP, Weintraub D, Stacy M. Impulsive and compulsive behaviors in Parkinson's disease. Mov Disord 2009;24:1561-1570.

2. Weintraub D, Koester J, Potenza MN, et al. Impulse control disorders in Parkinson disease: a cross-sectional study of 3090 patients. Arch Neurol 2010;67:589-595.

3. Wicks P, MacPhee GJ. Pathological gambling amongst Parkinson's disease and ALS patients in an online community (PatientsLikeMe.com). Mov Disord 2009;24:1085-1088.

4. Fan W, Ding H, Ma J, Chan P. Impulse control disorders in Parkinson's disease in a Chinese population. neurosci lett 2009;465:6-9.

5. Joutsa J, Martikainen K, Vahlberg T, Voon V, Kaasinen V. Impulse control disorders and depression in Finnish patients with Parkinson's disease. Parkinsonism \& related disorders 2012;18:155-160.

6. Corvol JC, Artaud F, Cormier-Dequaire F, et al. Longitudinal analysis of impulse control disorders in Parkinson disease. Neurology 2018;91:e189-e201.

7. Leroi I, Harbishettar V, Andrews M, McDonald K, Byrne EJ, Burns A. Carer burden in apathy and impulse control disorders in Parkinson's disease. International journal of geriatric psychiatry 2012;27:160-166.

8. Perez-Lloret S, Rey MV, Fabre N, et al. Do Parkinson's disease patients disclose their adverse events spontaneously? European journal of clinical pharmacology 2012;68:857-865.

9. Papay K, Mamikonyan E, Siderowf AD, et al. Patient versus informant reporting of ICD symptoms in Parkinson's disease using the QUIP: validity and variability. Parkinsonism \& related disorders 2011;17:153-155.

10. Rabinak CA, Nirenberg MJ. Dopamine agonist withdrawal syndrome in Parkinson disease. Arch Neurol 2010;67:58-63.

11. Okai D, Askey-Jones S, Samuel M, et al. Trial of CBT for impulse control behaviors affecting Parkinson patients and their caregivers. Neurology 2013;80:792-799.

12. Antonini A, Martinez-Martin P, Chaudhuri RK, et al. Wearing-off scales in Parkinson's disease: critique and recommendations. Mov Disord 2011;26:2169-2175.

13. Pavy-Le Traon A, Amarenco G, Duerr S, et al. The Movement Disorders task force review of dysautonomia rating scales in Parkinson's disease with regard to symptoms of orthostatic hypotension. Mov Disord 2011;26:1985-1992.

14. Weintraub D, Mamikonyan E, Papay K, Shea JA, Xie SX, Siderowf A. Questionnaire for Impulsive-Compulsive Disorders in Parkinson's Disease-Rating Scale. Mov Disord 2012;27:242-247.

15. Association AP. Diagnostic and Statistical Manual of Mental Disorders, Fourth Edition, Text Revision ed. Washington, DC: American Psychiatric Press, 2000.

16. Djamshidian A, O'Sullivan SS, Sanotsky Y, et al. Decision making, impulsivity, and addictions: do Parkinson's disease patients jump to conclusions? Mov Disord 2012;27:11371145. 
17. Claassen DO, van den Wildenberg WP, Ridderinkhof KR, et al. The risky business of dopamine agonists in Parkinson disease and impulse control disorders. Behav Neurosci 2011;125:492-500.

18. Auyeung M, Tsoi TH, Tang WK, et al. Impulse control disorders in Chinese Parkinson's disease patients: the effect of ergot derived dopamine agonist. Parkinsonism \& related disorders 2011;17:635-637.

19. Lim SY, Tan ZK, Ngam PI, et al. Impulsive-compulsive behaviors are common in Asian Parkinson's disease patients: assessment using the QUIP. Parkinsonism \& related disorders 2011;17:761-764.

20. Weintraub D, Hoops S, Shea JA, et al. Validation of the questionnaire for impulsivecompulsive disorders in Parkinson's disease. Mov Disord 2009;24:1461-1467.

21. American Psychiatric A. Diagnostic and Statistical Manual of Mental Disorders. Washington, DC: American Psychiatric Press, 1994.

22. Lejoyeux M, Tassain V, Solomon J, Ades J. Study of compulsive buying in depressed patients. J Clin Psychiatry 1997;58:169-173.

23. Voon V, Hassan K, Zurowski M, et al. Prevalence of repetitive and reward-seeking behaviors in Parkinson disease. Neurology 2006;67:1254-1257.

24. Giovannoni G, O'Sullivan JD, Turner K, Manson AJ, Lees AJ. Hedonistic homeostatic dysregulation in patients with Parkinson's disease on dopamine replacement therapies. J Neurol Neurosurg Psychiatry 2000;68:423-428.

25. Voon V, Fox SH. Medication-related impulse control and repetitive behaviors in Parkinson disease. Arch Neurol 2007;64:1089-1096.

26. Jimenez-Shahed J, Davidson T, Calhoun K, Jankovic J. Craving for sweets and other compulsive behaviors in patients with Parkinson's disease. Movement Disorders 2008;23:1348-1348.

27. Baumann-Vogel H, Valko PO, Eisele G, Baumann CR. Impulse control disorders in Parkinson's disease: don't set your mind at rest by self-assessments. European journal of neurology : the official journal of the European Federation of Neurological Societies 2015. 28. Ricciardi L, Demartini B, Pomponi M, et al. Impulsive compulsive behaviours in Parkinson's disease: patients' versus caregivers' perceptions. J Neurol 2016;263:1019-1021.

29. Goerlich-Dobre KS, Probst C, Winter L, et al. Alexithymia-an independent risk factor for impulsive-compulsive disorders in Parkinson's disease. Mov Disord 2014;29:214-220.

30. Probst CC, Winter LM, Moller B, et al. Validation of the questionnaire for impulsivecompulsive disorders in Parkinson's disease (QUIP) and the QUIP-rating scale in a German speaking sample. J Neurol 2014;261:936-942.

31. Grant JE, Steinberg MA, Kim SW, Rounsaville BJ, Potenza MN. Preliminary validity and reliability testing of a structured clinical interview for pathological gambling. Psychiatry Res 2004;128:79-88.

32. Martinez-Martin PR-B, C; Catalan, MJ and The EDIS Study Group. . Independent and complementary validation of the QUIP-RS in advanced Parkinson's disease. . Mov Disord Clin Pract 2018;in Press.

33. Biundo R, Weis L, Abbruzzese G, et al. Impulse control disorders in advanced Parkinson's disease with dyskinesia: The ALTHEA study. Mov Disord 2017;32:1557-1565. 
34. Morgante F, Fasano A, Ginevrino M, et al. Impulsive-compulsive behaviors in parkin-associated Parkinson disease. Neurology 2016;87:1436-1441.

35. Papay K, Xie SX, Stern M, et al. Naltrexone for impulse control disorders in Parkinson disease: a placebo-controlled study. Neurology 2014;83:826-833.

36. Ardouin C, Chereau I, Llorca PM, et al. [Assessment of hyper- and hypodopaminergic behaviors in Parkinson's disease]. Revue neurologique 2009;165:845-856.

37. Lhommee E, Klinger H, Thobois S, et al. Subthalamic stimulation in Parkinson's disease: restoring the balance of motivated behaviours. Brain 2012;135:1463-1477.

38. Rieu I, Martinez-Martin P, Pereira B, et al. International validation of a behavioral scale in Parkinson's disease without dementia. Mov Disord 2015;30:705-713.

39. Visser M, Verbaan D, van Rooden SM, Stiggelbout AM, Marinus J, van Hilten JJ. Assessment of psychiatric complications in Parkinson's disease: The SCOPA-PC. Mov Disord 2007;22:2221-2228.

40. Verbaan D, van Rooden SM, Visser M, Marinus J, Emre M, van Hilten JJ. Psychotic and compulsive symptoms in Parkinson's disease. Mov Disord 2009;24:738-744.

41. Martinez-Martin P, Frades-Payo B, Aguera-Ortiz L, Ayuga-Martinez A. A short scale for evaluation of neuropsychiatric disorders in Parkinson's disease: first psychometric approach. J Neurol 2012;259:2299-2308.

42. Campos LS, Guimaraes RP, Piovesana LG, Azevedo PC, Santos LM, D'Abreu A. Clinical predictors of cognitive impairment and psychiatric complications in Parkinson's disease. Arquivos de neuro-psiquiatria 2015;73:390-395.

43. Kurtis MM, Rodriguez-Blazquez C, Martinez-Martin P, Group E. Relationship between sleep disorders and other non-motor symptoms in Parkinson's disease. Parkinsonism \& related disorders 2013;19:1152-1155.

44. Weintraub D, Papay K, Siderowf A. Screening for impulse control symptoms in patients with de novo Parkinson disease: a case-control study. Neurology 2013;80:176-180. 45. Antonini A, Siri C, Santangelo G, et al. Impulsivity and compulsivity in drug-naive patients with Parkinson's disease. Mov Disord 2011;26:464-468.

46. Voon V, Sohr M, Lang AE, et al. Impulse control disorders in Parkinson disease: a multicenter case--control study. Ann Neurol 2011;69:986-996.

47. Okai D, Askey-Jones S, Samuel M, David AS, Brown RG. Predictors of response to a cognitive behavioral intervention for impulse control behaviors in Parkinson's disease. Mov Disord 2014.

48. Lawrence AD, Evans AH, Lees AJ. Compulsive use of dopamine replacement therapy in Parkinson's disease: reward systems gone awry? Lancet Neurol 2003;2:595-604.

49. Avanzi M, Baratti M, Cabrini S, Uber E, Brighetti G, Bonfa F. Prevalence of pathological gambling in patients with Parkinson's disease. Mov Disord 2006;21:2068-2072. 50. de Chazeron I, Llorca PM, Chereau-Boudet I, et al. Hypersexuality and pathological gambling in Parkinson's disease: A cross-sectional case-control study. Mov Disord 2011;26:2127-2130.

51. Lee JY, Kim JM, Kim JW, et al. Association between the dose of dopaminergic medication and the behavioral disturbances in Parkinson disease. Parkinsonism \& related disorders 2010;16:202-207. 
52. Voon V, Hassan K, Zurowski M, et al. Prospective prevalence of pathologic gambling and medication association in Parkinson disease. Neurology 2006;66:1750-1752.

53. Evans AH, Lawrence AD, Potts J, Appel S, Lees AJ. Factors influencing susceptibility to compulsive dopaminergic drug use in Parkinson disease. Neurology 2005;65:1570-1574.

54. Kalichman SC, Rompa D. The Sexual Compulsivity Scale: further development and use with HIV-positive persons. Journal of personality assessment 2001;76:379-395.

55. Holden C. 'Behavioral' addictions: do they exist? Science 2001;294:980-982.

56. Hollander E, Kim S, Khanna S, Pallanti S. Obsessive-compulsive disorder and obsessive-compulsive spectrum disorders: diagnostic and dimensional issues. CNS spectrums 2007;12:5-13. 
Table 1: Conclusions regarding Scale Classification for ICB Diagnostic Screening and Severity Rating

\begin{tabular}{|c|c|c|c|c|c|}
\hline Scale & $\begin{array}{l}\text { Used } \\
\text { in PD }\end{array}$ & $\begin{array}{l}\text { Use by other } \\
\text { investigators } \\
\text { in PD }\end{array}$ & $\begin{array}{l}\text { Adequate } \\
\text { Clinimetrics } \\
\text { in nonPD } \\
\text { and Further } \\
\text { Clinimetrics } \\
\text { in PD }\end{array}$ & $\begin{array}{l}\text { Classification } \\
\text { for diagnostic } \\
\text { screening }\end{array}$ & $\begin{array}{l}\text { Classification for } \\
\text { Severity Rating }\end{array}$ \\
\hline \multicolumn{6}{|c|}{ Scales covering the range of ICBs } \\
\hline $\begin{array}{l}\text { Questionnaire } \\
\text { for Impulsive- } \\
\text { Compulsive } \\
\text { Disorders in } \\
\text { Parkinson's } \\
\text { disease (QUIP) }\end{array}$ & $\mathrm{x}$ & $\mathrm{x}$ & $\mathrm{x}$ & Recommended & N/A \\
\hline $\begin{array}{l}\text { QUIP-Rating } \\
\text { Scale (QUIP-RS) }\end{array}$ & $\mathrm{X}$ & $\mathrm{X}$ & $\mathrm{x}$ & Recommended & Recommended \\
\hline $\begin{array}{l}\text { Self-assessment } \\
\text { scale for } \\
\text { dopamine } \\
\text { dependent } \\
\text { behaviors in } \\
\text { Parkinson's } \\
\text { disease (Ardouin } \\
\text { short screen) }\end{array}$ & $\mathrm{X}$ & $\mathrm{x}$ & $\mathrm{x}$ & N/A & Recommended \\
\hline $\begin{array}{l}\text { Scale for } \\
\text { Outcomes in } \\
\text { Parkinson's } \\
\text { disease - } \\
\text { Psychiatric } \\
\text { Complications } \\
\text { (SCOPA-PC) }\end{array}$ & $\mathrm{X}$ & $\mathrm{X}$ & $\mathrm{X}$ & N/A & $\begin{array}{l}\text { Recommended for } \\
\text { hypersexuality, } \\
\text { gambling/shopping }\end{array}$ \\
\hline $\begin{array}{l}\text { Minnesota } \\
\text { Impulsive } \\
\text { Disorders } \\
\text { Interview (MIDI) }\end{array}$ & $\mathrm{x}$ & $\mathrm{x}$ & & Suggested & N/A \\
\hline $\begin{array}{l}\text { The Parkinson's } \\
\text { Impulse Control } \\
\text { Scale (PICS) }\end{array}$ & $\mathrm{x}$ & & $\mathrm{x}$ & Suggested & Suggested \\
\hline $\begin{array}{l}\text { Scale for } \\
\text { Evaluation of } \\
\text { Neuropsychiatric } \\
\text { Disorders in } \\
\text { Parkinson's } \\
\text { Disease (SEND- } \\
\text { PD) }\end{array}$ & $\mathrm{x}$ & & $\mathrm{X}$ & N/A & Suggested \\
\hline
\end{tabular}




\begin{tabular}{|c|c|c|c|c|c|}
\hline $\begin{array}{l}\text { Parkinson's } \\
\text { disease } \\
\text { dopamine } \\
\text { dysregulation } \\
\text { syndrome- } \\
\text { patient and } \\
\text { caregiver } \\
\text { inventory (DDS- } \\
\text { PC) }\end{array}$ & $\mathrm{x}$ & & $\mathrm{x}$ & N/A & Suggested \\
\hline \multicolumn{6}{|c|}{ Scales focusing on individual ICBs } \\
\hline $\begin{array}{l}\text { South Oaks } \\
\text { Gambling Screen } \\
\text { (SOGS) }\end{array}$ & $\mathrm{X}$ & $\mathrm{x}$ & & Suggested & Suggested \\
\hline $\begin{array}{l}\text { Evans' punding } \\
\text { screen and } \\
\text { rating scale }\end{array}$ & $\mathrm{x}$ & $\mathrm{x}$ & $\mathrm{x}$ & Suggested & Listed \\
\hline $\begin{array}{l}\text { Punding Rating } \\
\text { Scale }\end{array}$ & $\mathrm{x}$ & & $\mathrm{x}$ & Suggested & Suggested \\
\hline $\begin{array}{l}\text { Shorter version } \\
\text { of the Sexual } \\
\text { Addiction } \\
\text { Screening Test } \\
\text { (PD-SAST) }\end{array}$ & $\mathrm{x}$ & & $\mathrm{x}$ & Suggested & Suggested \\
\hline $\begin{array}{l}\text { Saving Inventory } \\
\text { - Revised (SI-R) }\end{array}$ & $\mathrm{x}$ & & $\mathrm{x}$ & Suggested & Suggested \\
\hline $\begin{array}{l}\text { The Pathological } \\
\text { Gambling } \\
\text { Adaption of the } \\
\text { Yale-Brown } \\
\text { Obsessive- } \\
\text { Compulsive } \\
\text { Scale } \\
\text { (PG-YBOCS) }\end{array}$ & $\mathrm{X}$ & & $\mathrm{X}$ & N/A & Suggested \\
\hline $\begin{array}{l}\text { Gambling } \\
\text { Symptom } \\
\text { Assessment } \\
\text { Scale (G-SAS) }\end{array}$ & $\mathrm{X}$ & & $\mathrm{X}$ & N/A & Suggested \\
\hline $\begin{array}{l}\text { Compulsive } \\
\text { Buying Scale } \\
\text { (CBS) }\end{array}$ & $\mathrm{x}$ & & $\mathrm{x}$ & N/A & Suggested \\
\hline
\end{tabular}




\section{University Library}

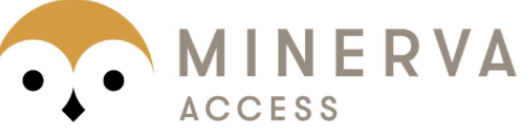

A gateway to Melbourne's research publications

Minerva Access is the Institutional Repository of The University of Melbourne

\section{Author/s:}

Evans, AH;Okai, D;Weintraub, D;Lim, S-Y;O'Sullivan, SS;Voon, V;Krack, P;Sampaio, C;Post, B;Leentjens, AFG;Martinez-Martin, P;Stebbins, GT;Goetz, CG;Schrag, A;Bhidayasiri, R;Brown, RG;Marinus, J;Mestre, TA;Violante, MR;Skorvanek, M

Title:

Scales to assess impulsive and compulsive behaviors in Parkinson's disease: Critique and recommendations

\section{Date:}

2019-06-01

\section{Citation:}

Evans, A. H., Okai, D., Weintraub, D., Lim, S. -Y., O'Sullivan, S. S., Voon, V., Krack, P., Sampaio, C., Post, B., Leentjens, A. F. G., Martinez-Martin, P., Stebbins, G. T., Goetz, C. G., Schrag, A., Bhidayasiri, R., Brown, R. G., Marinus, J., Mestre, T. A., Violante, M. R. \& Skorvanek, M. (2019). Scales to assess impulsive and compulsive behaviors in Parkinson's disease: Critique and recommendations. MOVEMENT DISORDERS, 34 (6), pp.791-798. https://doi.org/10.1002/mds.27689.

Persistent Link:

http://hdl.handle.net/11343/285894 